happens mechanically to underground strata when explosions take place. It seems widely to be agreed that the problem is to predict what happens when rocks are exposed to pressures of about a million bars decaying to about a hundred bars in a hundred seconds. Computer programs have been used to estimate the varying effects of different kinds of rock. Much of what happens underground seems to depend on the rate at which the internal pressure in the cavity decays by heat loss into the surrounding rock, itself determined by the conductivity of the materials. Although scaling up the results of small explosions to predict the effects of larger ones is apparently of considerable if limited value, the prediction of chemical processes underground is more difficult.

Chemical uncertainties have a bearing on the problem of vented radioactivity. There seems to be some uncertainty about the ideal behaviour of underground explosions and necessarily about the radioactive consequences of cratering explosions. In one calculation presented at the conference, on the assumption that only ten out of a hundred kilotons of a Plowshare explosion is derived from fission, the hazards from radioactivity involved in building underground structures such as storage reservoirs for natural gas or oil would consist only of radioactive tritium, and there is even a chance that this might be removed by bleaching. Experience with the Gasbuggy underground explosion two years ago, intended to produce a supply of natural gas, seems to have been that radioactive iodine is not a hazard, but that tritium and radioactive krypton are the chief sources of hazard, especially if the gas is distributed (which has not yet been attempted). On the success of the Gasbuggy experiment as an economic enterprise, speakers at the conference estimated that the El Paso Natural Gas Company of Texas will eventually be able to recover 19 per cent of the gas originally in place under the 160 acre site. The fractures produced by the underground explosion seem to extend sufficiently far to promise steady operation of such a well, but the gas withdrawn from the Gasbuggy hole seems to have been diluted to half its volume by a mixture of carbon dioxide and hydrogen produced, it is assumed, in the explosion. In the past two years, however, the hydrocarbon content of the gas has increased to 90 per cent as the original products have been swept to the surface.

The use of nuclear explosions for mining ores has been tested by a number of explosions in the past few years, but it seems that much depends on whether ore bodies are correctly placed with respect to the surface for the technique to be usable. The release of oil from oil shale was also described at the conference, as was the production of relatively large amounts of heavy nuclides by the exposure of uranium and thorium targets to the neutron flux of an underground explosion-it now seems probable that the Hutch underground explosion will have produced in this way 10,000 million atoms of fermium-257-a hundred times as much as previously obtained. For the most part, however, interest still centres on excavation schemes such as the Panama Canal and the scheme called Project Carryall intended to drive a combined railway and road through the western desert of the United States. One new candidate at the conference was a proposal to drive a canal from the Mediterranean through the Gulf of Gabes in Tunisia to the large tract of land in Algeria and Tunisia that lies below sea level.
Potential benefits are said to include a seaway to help with removing oil and minerals, a tourist trade and even climatic change. It is calculated by a group from the Georgia Institute of Technology that the whole project could be mounted for $\$ 710$ million spread over seven years.

\section{SCIENCE POLICY Harvard Program Soldiers on}

The Program on Technology and Society at Harvard University seems to have followed its own advice, made public a year ago, by paying more attention to the relationship between technology and what is called "the life of the individual". This is the chief interest of the annual report for 1968-69, now published. The research programme has been supplemented by projects intended to examine the effects of technological change on work and leisure, and the staff has also begun on a long-term inquiry into the psychological adaptability of people at work. The Program continues to occupy itself with its unique blend of sociology and technology.

The study of the relationship between work and leisure, the responsibility of Harold L. Wilensky, professor of sociology at Berkeley, has been based on a survey among 1,354 men in jobs as different as university professors and manual workers. The sample has been deliberately biased so as to include within each category of workers the most and the least progressive kinds of jobs. The hope is that an analysis of this population will suggest how people in different kinds of jobs choose between income and leisure. Professor Wilensky has established that television plays a dominating part in the use made of leisure time, and he has now resolved to concentrate on "the quality of the television experience". Briefly, he seems to have found that men with boring jobs spend what leisure they have looking at the television screens, however bad the material to be seen, but that men with more intellectually demanding jobs spend their leisure in more interesting ways as well.

The other new project, still at the planning stage, is being organized by Dr Michael Maccoby, from the Institute of Policy Studies in Washington, DC. $\mathrm{He}$ intends to begin with a careful study of a chosen company. The first objective will be an attempt to define the psychological attributes demanded by different kinds of industrial work. The long-term goal is to understand which kinds of people are successful at their jobs and to find out which intellectual abilities are stimulated by particular jobs. Dr Maccoby starts his work with a few preconceptions, among which is the suspicion that the kinds of intellectual skills best suited to success in modern industry may be different from "the abstract intelligence currently dominant in our society and reflected by standard IQ tests".

Among the continuing work of the Program on Technology and Society is a scheme for examining the extent to which the arrival of computers will affect the working of public authorities. Professor Alan F. Westin, from Columbia University, is among other things concerned with the classical Big Brother question of whether the storage of large amounts of information in publicly used computers will eventually lead to situations in which legislation and the conduct of daily operations in public authorities are tailored so as to suit the convenience of the computer programmers. 